\title{
Digital Literacy \& Digital Skills Scenario of ASEAN Marginal Workers Under \& Post COVID-19 Pandemic
}

\section{Kamolrat Intaratat}

School of Communication Arts, The Research Center of Communication and Development Knowledge Management (CCDKM), Sukhothai Thammathirat Open University (STOU), Nonthaburi, Thailand

Email: kamolratchim@gmail.com

How to cite this paper: Intaratat, $\mathrm{K}$. (2022). Digital Literacy \& Digital Skills Scenario of ASEAN Marginal Workers Under \& Post COVID-19 Pandemic. Open Journal of Business and Management, 10, 118-133.

https://doi.org/10.4236/ojbm.2022.101007

Received: October 8, 2021

Accepted: December 28, 2021

Published: December 31, 2021

Copyright $\odot 2022$ by author(s) and Scientific Research Publishing Inc. This work is licensed under the Creative Commons Attribution International License (CC BY 4.0).

http://creativecommons.org/licenses/by/4.0/

\begin{abstract}
This research aims to study 1) the scenario of workforces relevant with digital literacy and digital skills among the marginal workers from the selected six ASEAN countries; 2) the scenario of the digital literacy and digital skills relevant to the current and the future jobs skills among all the marginal workers; and 3) the government's policy to support any digital reskill-upskilling among the workforces including the marginal workers to serve well with all demanding skills of the future jobs. The qualitative research with document study and e-interview among all 178 key informants from all relevant stakeholders by its clustered sampling: the policy, the private sector, and the marginal workers from the selected six ASEAN countries base on their similar digital literacy and digital skills workforces context. Narrative description was used. The article organizes its findings as of its objectives 1) the scenario of workforces relevant with digital literacy and digital skills among all the marginal workers from the selected ASEAN countries affected by the pandemic as well as technology disruption resulted in a pattern of businesses shifting from the formal sector to the informal and will be most affected the low skilled. The future of work has already arrived for a large majority of the online white-collar workforce. Eighty-four percent of employers are set to rapidly digitalize working processes, including a significant expansion of remote work with its trend to change $44 \%$ of their workforce to operate remotely; 2 ) The scenario of the digital literacy and digital skills relevant to the current and the future jobs skills among all the marginal workers found the top emerging jobs relevant to digital literacy and digital skills are data analysts \& data scientists, digital marketing specialist, software and application developer, YouTubers, Start Ups, and some of the soft skills such as the creative \& the analytical thinking, problem-solving, and others. All kinds of administrative
\end{abstract}


jobs, secretaries, accounting, bookkeeping, payroll clerk, HR would be declining. Most of the marginal workers have low to mid digital literacy and digital skills such as Microsoft office, digital marketing, photoshop, social media, content creating, and video editing. They are looking forward to reskills in all related digital literacy and digital skills from fundamental to mid and high skills such as data analytic, data science, software development, web development, cybersecurity, AI, programing, cyber manager, digital consultant and others; 3) The government's policy relevant to support any reskill-upskilling among the workforces including the marginal workers for future jobs found similar among ASEAN with a) accelerate all relevant digital competency by partnering with private and industry sectors through TVET training system; and b) work with industries to revamp national curriculums via digital learning pathway and emerging skillsets. The PPP strategy must be used for knowledge transfer and building digital ecosystem.

\section{Keywords}

Digital Literacy, Digital Skills, ASEAN, Marginal Workers, COVID-19

Pandemic

\section{Introduction}

The global and regional pandemic of COVID-19, besides from all kinds of disruptive technologies and innovations demanding, affected all recession globally and regionally since 2019 till now. In 2020, the tangible effects were seen in the labor market and accelerated the arrival of the future of work from its pandemic-related disruptions and the technology adoption relevant in jobs and skills in the next five years despite the currently high degree of uncertainty by its nature and challenges among Southeast Asia (ASEAN) with their own differences stages of development, economic structure, policy to support all growth strategies, demographic profile, institutional capacity and workforce demanding and their abilities and effectiveness in responding to the skill needs of industry (The Future of Jobs Report, 2020).

Under this regional and global recession brought on by the COVID-19 pandemic and technology disruption affected millions of workers especially among all the marginalized who lack digital literacy and digital skills for all disruption. A shortage of new digital skill-based workers is one of the biggest challenges for ASEAN comprising Singapore, Malaysia, Thailand, Indonesia, the Philippines, and Vietnam represents one of the most dynamic and promising growth regions in the world today. The implementation of the ASEAN Economic Community (AEC) initiatives and the anticipated formation of the Trans-Pacific Partnership (TPP) and other regional economic integration groupings could significantly expand trade and investment and unleash powerful forces of competition in the region, raising productivity levels and growth rates in the region. 
However, whether ASEAN could successfully achieve robust and sustainable growth depends crucially on their abilities to equip their workforce with general and job-specific skills needed by the growth industries they are promoting. So, this research explores the scenario of workforces relevant with digital literacy and digital skills among all the marginal workers who are affected by lack of economic opportunity due to their lack of digital literacy and digital skills under the pandemic of COVID-19 and technology disruption. The benefits from this study aim to be used for its planning to prepare all workforces especially the marginal workers in the demanding future of jobs and skills related to digital literacy and digital skills as well as all relevant contexts i.e. related government policies, and public-private partnership to be ready under each country's situation where COVID-19 pandemic and digital technologies are shaping the future of the jobs (Tan \& Tang, 2016).

\section{Literature Review}

The COVID-19 pandemic-induced lockdowns and related global recession of 2020 have created a highly uncertain outlook for the labor market and accelerated the arrival of the future of work. The Future of Jobs Report (2020) aims to shed light on: 1) the pandemic-related disruptions thus far in 2020, contextualized within a longer history of economic cycles, and 2) the expected outlook for technology adoption jobs and skills in the next five years. Despite the currently high degree of uncertainty, the report uses a unique combination of qualitative and quantitative intelligence to expand the knowledge base about the future of jobs and skills. It aggregates the views of business leaders-chief executives, chief strategy officers and chief human resources officers-on the frontlines of decision-making regarding human capital with the latest data from public and private sources to create a clearer picture of both the current situation and the future outlook for jobs and skills.

In 2020, economic globalization is stalling, social cohesion is being eroded by significant unrest and political polarization, and an unfolding recession is threatening the livelihoods of those at the lower end of the income spectrum. As a new global recession brought on by the COVID-19 health pandemic impacts economies and labor markets, millions of workers have experienced changes which have profoundly transformed their lives within and beyond work, their well-being, their productivity and their quality of lives. Because of the Lack of economic opportunity from lacking of all relevant technology and tech-enabled knowledge and skills to achieve high-wage, high-growth jobs especially all the job in the future which require digital fluency. Yet, people from underserved communities and communities are consistently underrepresented in technology. COVID-19, economic recession and digital transformation have deepened the digital divide; the negative impact existed before and isn't going away anytime soon (School of Economics, 2016).

Since late 2019, more parts keep increasing to automation, digital technology 
and digitization globally affected more and more risks to labor market stability, significant and unexpected disruption especially among the marginalized workers besides the COVID-19 pandemic appears to be deepening all difficulties across labor markets. The changes heralded by the COVID-19 pandemic have affected all kinds of changes triggered by the Fourth Industrial Revolution, which has consequently increased in velocity and depth. Figure 1 shows the new digital skills needed in and after a COVID-19 economy (Smith, 2020) (Figure 1).

From the above data, 10 jobs were identified as having the greatest number of job openings, have had steady growth over the past four years, pay a livable wage, and require skills that can be learned online: Become a Software Developer, Become a Sales Representative, Become a Project Manager, Become an IT administrator (Prepare for CompTIA Network+ Certification), Become a Customer Service Specialist, Become a Digital Marketing Specialist, Become IT Support/Help Desk (Prepare for the CompTIA A+ Certification), Become a Data Analyst, Become a Financial Analyst, and Become a Graphic Designer (Smith, 2020).

By 2025, tasks at work by humans and machines will be equal. A significant share of companies also expects to make changes to locations, value chains, and the size of workforce due to technology. Number of jobs destroyed will be surpassed by the number of "jobs of tomorrow" created by 2025, 85 million jobs may be displaced by a shift in the division of labor between humans and machines, while 97 million new jobs may emerge more adapted to the new division of labor between humans, machines and algorithms. Digital skills gaps continue to be high as well as some of the soft skills such as critical thinking and analysis, problem-solving, self-management such as active learning, resilience, stress tolerance and flexibility.
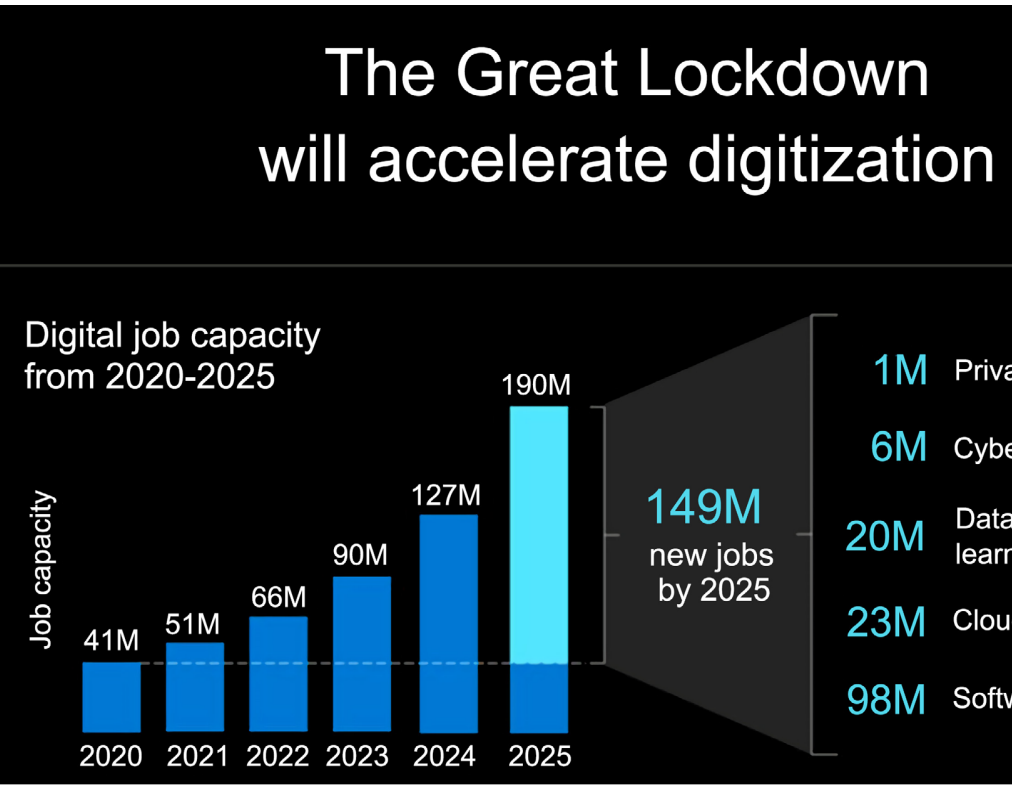

$1 \mathrm{M}$ Privacy and trust

$6 \mathrm{M}$ Cyber security

20M Data analysis, machine learning, and $\mathrm{Al}$

23M Cloud and data roles

98M Software development

Figure 1. New digital skills needed in and after a COVID-19 economy (Smith, 2020). 
Jobs held by marginal workers, women and youths were more deeply impacted in the first phase of the economic contraction. Comparing the impact of the Global Financial Crisis of 2008 on individuals with lower education levels to the impact of the COVID-19 crisis, the impact today is far more significant and more likely to deepen existing inequalities. The reskill and upskill become shorter in the newly constrained labor market. A significant number of business leaders understand that reskilling employees, particularly in industry coalitions and in public-private collaborations both cost-effective and significant to long-term dividends not only for their enterprise but also for the benefit of society. More demands from all sectors especially the public sector to provide stronger support for reskilling and upskilling to all at-risk or displaced workers. Currently, only $21 \%$ of businesses report is able to make use of public funds to support their employees through reskilling and upskilling for all tomorrow jobs under the midst of job transitions (The Future of Jobs Report, 2020).

With all disruptions and demands, this study can be the solution to serve the real development of ASEAN workforces relevant with digital literacy and digital skills.

\section{Research Objectives}

1) To study the scenario of workforces relevant with digital literacy and digital skills among all the marginal workers from each selected ASEAN country;

2) To study the scenario of the digital literacy and digital skills relevant to the current and the future jobs skills among all the marginal workers;

3) To study the government's policy relevant to support any digital reskill-upskilling among the workforces including the marginal workers to serve well with all demanding skills of the future jobs.

\section{Research Method}

A qualitative research method involved with an e-interview and desk research focused on 6 ASEAN member countries which have the similar contexts of digital literacy \& digital skills among their workforces: Indonesia, Malaysia, Philippines, Singapore, Thailand and Vietnam. The e-Interviews have been made to 178 key informants who are urban migrant job seekers, fresh graduated students, private sector, business association, and government agencies in respective 6 targeted countries to understand country's situation where COVID-19 pandemic and digital technologies are disrupting and shaping the future of their workforces.

\section{Findings and Discussion}

Findings from each selected ASEAN country presented under its objectives respectively: 1) Country scenario, 2) Digital literacy and digital skills of workers, and 3) Policy to support digital literacy and digital skills post COVID-19. 


\subsection{Indonesia}

1) Country scenario composed of its general information relevant to digital economy and its effects from technology disruption and COVID-19 pandemic found Indonesia as its largest economy in ASEAN and the world's fourth most population with the world's 10 largest economies in terms of purchasing power, and also being a member of G20. Its industry focus for growth, employment, and 4IR in food \& beverage and automotive manufacturing. Furthermore, it has made enormous gains in poverty reduction, cutting the poverty rate by more than half since 1999 , to $9.78 \%$ in 2020 . Industry prior to the COVID-19 was able to maintain consistent economic growth, qualifying to reach upper middle-income status.

Pandemic officially in early March 2020 with its massive spread affected in economic activity, household consumption, investment, and financial institutions. Loss of income especially among the vulnerable groups under the informal sector brought to economic shocks due to lacking digital skills. The decline occurred at the MSMEs, the corporate sector in manufacturing, trade, transportation causes loss of employment and even bankruptcy.

Government policy relevant to the digital job skills found the Investment Coordinating Board (BKPM) estimates at least 17 million new jobs will be unemployed workers due to the COVID-19 pandemic consisting of low skilled employees, and a new graduate. Informal workers (55\%), youths (17.6\%) are most affected. More women are likely to be informally employed than men, and generally receive lower pay and mostly unpaid in the agriculture and construction industries. Pandemic resulted in a pattern of businesses shifting from the formal sector to the informal which affected women workers the most. The policy e-Interview stated that industry to be promoted post pandemic are tourism, transportation, F\&B, SME, start up, digital entrepreneur, digital village since they are the economy backbone to accelerate digital economy.

2) Digital literacy and Digital skills found the rise of digital infrastructure projects to serve the emerging jobs demands analyzed by Linkedin 2020 found Data Analysts \& Scientists which also aligned with the e-Interview found Data Scientist, Machine learning engineer. While the e-Interview with 27 samples found women has low digital skill than male i.e. basic and intermediate Microsoft office, photoshop, Social media, content creating, SEO while male have middle-high digital skills and digital marketing, e-transactional skills. Workers are looking forward to train new skills; AI, Big Data, Cloud Computing, Internet of Things, Website development, Coding, Data \& digital marketing, Online entrepreneurship, Photoshop, Graphic design as shown in Table 1.

3) Government policy to support digital literacy and digital skills post COVID-19 has started programs to address digital infrastructure and human resources capability. Highlighted programs are Making Indonesia 4.0 "Upgrade Human Capital" to transform workforce into the information technology sector, Quality Work-Based Learning Program, Gerakan Nasional Literasi Digital to 
Table 1. Top emerging jobs analyzed by WEF, Linkedin, and the current interview 2021.

Data Analyst, Data Scientist, AI and Machine Learning Specialist are top emerging tech-enabled roles beneficiary need for job opportunity/better living

\begin{tabular}{|c|c|c|}
\hline Across industries ranking & Across industries & \\
\hline $\begin{array}{l}\text { Source: World Economic Forum } \\
\text { (WEF) }\end{array}$ & $\begin{array}{l}\text { ranking } \\
\text { Source: LinkedIn }\end{array}$ & Source: E-Interview \\
\hline 1. Data Analysts and Scientists & 1. AI Specialist & $\begin{array}{l}\text { 1. Data Analyst, data scientist, } \\
\text { data architect, data engineer }\end{array}$ \\
\hline $\begin{array}{l}\text { 2. AI and Machine Learning } \\
\text { Specialists }\end{array}$ & 2. DevOps Engineer & $\begin{array}{l}\text { 2. Digital marketer, digital } \\
\text { servicer }\end{array}$ \\
\hline 3. Big Data Specialists & $\begin{array}{l}\text { 3. Customer Success } \\
\text { Specialist }\end{array}$ & 3. Microsoft Office \\
\hline $\begin{array}{l}\text { 4. Digital Marketing and Strateg } \\
\text { Specialists }\end{array}$ & $\mathrm{y}_{4 .}$ Data Scientist & $\begin{array}{l}\text { 4. Video Production, Graphic } \\
\text { Design }\end{array}$ \\
\hline 5. Process Automation Specialis & 5. JavaScript Developer & 5. AI \\
\hline
\end{tabular}

serve digital transformation aims to provide digital literacy to 12.4 million people as well as to support the underserved to gain new digital skills. The pre-work cards (kartu pra-kerja) as training fee support the excluded workers to get up-to-date skills and ready-to-work workers.

More policy to move digital skilling are: 1) accelerate workforce digital competency by partnership; 2) working with industry to revamp curriculums via digital pathway and emerging skillsets. e-Interview indicates the PPP as the key strategy to building digital ecosystem.

\subsection{Malaysia}

1) Country scenario composed of its general information relevant to digital economy and its effects from technology disruption and COVID-19 pandemic found Malaysia under its transition to a high-income economy between 2024 and 2028 by using economic transformation development focus for growth, employment, and 4IR i.e. Electrical \& Electronic, Machinery \& Equipment, Healthcare, Medical Device, Telecommunication, Oil \& Gas. COVID-19 has accelerated the adoption of digitalization in all sectors: businesses, education and society. The economic value of digital trade-enabled benefits to the country economy RM222 billion by 2030 from RM31 billion in 2019 (Kementerian Pelajaran Malaysia, 2012).

Pandemic hit in March 2020 affected the unemployment to 4.8 percent with relatively high among the marginalized especially youth and women. Over $60 \%$ of job losses in the private sector were the jobs earning under RM3000 per month. The pandemic has also unexpectedly displaced higher-skilled workers, with 39 percent of job losses concentrated among managers and professionals while three-quarters of new placements were in jobs earning under RM1500 per month. 
The policy interview stated that the industry to be promoted after pandemic are tourism, transportation, F\&B, SME, start up, digital entrepreneur, digital village.

2) Digital literacy and Digital skills has created new ways of doing business and diversifying the economy highly required by embracing technological advances under the Industrial Revolution 4.0 and digitalization of business ecosystem. The emerging top Jobs analyzed by LinkedIn 2020 are data analysts \& scientists, digital marketing specialist, software and application developer, YouTubers and Start Ups which are also aligned with the e-Interview. While e-Interview from 37 samples found most of Malaysian workforces have been excluded even with their mid \& high digital skills, yet they also willing to reskills/upskills and prefer workshop training with online. Currently, they have foundational skills such as Microsoft office, digital marketing, photoshop, Social media, content creating, video editing. They are looking forward to receiving more training in data analytic, data science, software \& web development, cybersecurity, and advanced digital marketing skills in Table 2.

3) Policy to support digital literacy and digital skills post COVID-19 found various stages of the Movement Control Order (MCO) since 2020 to curb the transmission of COVID-19, the Government has embarked on a series of economic stimulus measures totalling RM305 billion entailing fiscal and non-fiscal measures. The Economic Stimulus Package Prihatin Rakyat was unveiled in March 2020, followed by the PRIHATIN SME+ in April, short-term Economic Recovery Plan (PENJANA) in June and in September the PRIHATIN Supplementary Initiative Package. Moreover, the government launched the MyDigital expected to create 500,000 jobs in the digital economy aims to contribute 22.6 percent to the country's gross domestic product (GDP).

More policy in digital skilling are: 1) promote the public and private sectors to synergize in all the challenges; 2) accelerate workforce digital competency by

Table 2. Top emerging jobs analyzed by WEF, Linkedin, and the current interview 2021.

Data Analysts, Data Scientists, Digital Marketing Specialist, Software and application developer are top emerging jobs across industries in Malaysia.

\begin{tabular}{|c|c|c|}
\hline $\begin{array}{l}\text { Across industries ranking } \\
\text { Source: World Economic Forum } \\
\text { (WEF) }\end{array}$ & $\begin{array}{l}\text { Across industries } \\
\text { ranking } \\
\text { Source: LinkedIn }\end{array}$ & Source: e-Interview \\
\hline 1. Data Analysts and Scientists & 1. Data Scientist & $\begin{array}{l}\text { 1. Data Analyst, data scientist, } \\
\text { data architect, data engineer }\end{array}$ \\
\hline $\begin{array}{l}\text { 2. AI and Machine Learning } \\
\text { Specialists }\end{array}$ & $\begin{array}{l}\text { 2. Customer Success } \\
\text { Specialist }\end{array}$ & $\begin{array}{l}\text { 2. Digital marketer, digital } \\
\text { servicer }\end{array}$ \\
\hline 3. Big Data Specialists & 3. BIM Specialist & 3. Digital Project Management \\
\hline $\begin{array}{l}\text { 4. Digital Marketing and Strategy } \\
\text { Specialists }\end{array}$ & 4. Full Stack Engineer & $\begin{array}{l}\text { 4. Digital skills set (Platform, } \\
\text { Cloud) }\end{array}$ \\
\hline 5. Process Automation Specialist & 5. Data Engineer & 5. AI, Google Analyst \\
\hline
\end{tabular}


partnering with private sector, industry by TVET training; 3) working with industry to revamp national curriculums with digital learning pathway and emerging skillsets. E-Interview indicates PPP to harness the best practice and scale to broader citizen.

\subsection{The Philippines}

1) Country scenario composed of its general information relevant to digital economy and its effects from technology disruption and COVID-19 pandemic found being one of the most dynamic economies in ASEAN with its increasing urbanization, a growing middle class, and a large young population. Its economic dynamism is supported by a vibrant labor market with business activities notable in services sector including business process outsourcing, real estate, tourism, finance and insurance industries. Sound economic fundamentals and a globally recognized competitive workforce reinforce the growth momentum. Having sustained average annual growth of $6.4 \%$ between 2010-2019 from an average of $4.5 \%$ between $2000-2009$, the country is on its way from a lower middle-income country to an upper middle-income country (per capita income range of US $\$ 4046$ - $\$ 12,535$ ) in the near term.

Pandemic was on January 30, 2020, more than 1.4 million cases have been reported but still confident that the GDP would return back by early next year. However, the recovery will remain at risk. The country's unemployment rate in April 2021 was estimated at 8.7 percent.

2) Digital literacy and Digital skills relies on the government and private industry who played lead roles in the Information Technology (IT) of the country. The government provides infrastructure, leading-edge IT applications, lead the key IT projects for participation and implementation by businesses, academes, the science and technology community, and the civil society as shown in Table 3.

3) Policy to support digital literacy and digital skills post COVID-19 found the Industry 4.0 transformation roadmaps led by joint committee (consisting of DTI, DOST and Department of Labor and Employment [DOLE]), coordinating with industry, employer associations and higher educational institutions. Develop a series of industry-led technical vocational education and training programs for Industry 4.0 by TVET curricula.

About the excluded groups found over $56 \%$ or around 10.9 million are informal workers as their low skills, not protected by employment laws and $38 \%$ are women in the declining industries such as wholesale, retail, accommodation, food service activities, and part-time workers. Also affected to most of the fresh graduates and youth (aged 15 - 24) around 1.7 million at risk. While the e-interview with 32 samples found the most excluded groups are the migrant urban workers, mid skilled workers then informal workers and the University Graduates with their average age 30 - 45, and more females. Education is more on high school, Degree, and No education. All are at the Operational level such as clerk, office 
Table 3. Top emerging jobs analyzed by WEF, Linkedin, and the current interview 2021.

Data Analysts, Data Scientists, Digital Marketing Specialist, Software and application developer are top emerging jobs across industries in Thailand.

\begin{tabular}{|c|c|c|}
\hline $\begin{array}{l}\text { Across industries ranking } \\
\text { Source: World Economic } \\
\text { Forum (WEF) }\end{array}$ & $\begin{array}{l}\text { Across industries } \\
\text { ranking } \\
\text { Source: LinkedIn }\end{array}$ & Source: e-Interview \\
\hline 1. Data Analysts and Scientists & 1. Robotics Engineer & 1. Video making and editing \\
\hline $\begin{array}{l}\text { 2. AI and Machine Learning } \\
\text { Specialists }\end{array}$ & $\begin{array}{l}\text { 2. Cyber Security } \\
\text { Specialist }\end{array}$ & $\begin{array}{l}\text { 2. Web design and graphics } \\
\text { design }\end{array}$ \\
\hline 3. Big Data Specialists & $\begin{array}{l}\text { 3. Customers Success } \\
\text { Specialist }\end{array}$ & $\begin{array}{l}\text { 3. MS Excel, Google Sheets, } \\
\text { PowerPoint }\end{array}$ \\
\hline $\begin{array}{l}\text { 4. Digital Marketing and Strategy } \\
\text { Specialists }\end{array}$ & 4. Data Scientist & 4. Coding \\
\hline $\begin{array}{l}\text { 5. Process Automation } \\
\text { Specialist }\end{array}$ & $\begin{array}{l}\text { 5. Sales Development } \\
\text { Representative }\end{array}$ & $\begin{array}{l}\text { 5. Cloud Technology, } \\
\text { Machine Learning and } \\
\text { Artificial Intelligence }\end{array}$ \\
\hline
\end{tabular}

staff, Secretariat, Janitress, Building attendant, Food Delivery. Their general Digital Skills are mostly low-mid with MS Office, Social Media, VDO producer, Web Design, forced to leave jobs because of not enough Digital Skills and ageing.

The current policy to support the digital skills for workforces are; 1) Industry 4.0 transformation roadmaps: DTI, DOST and Department of Labor and Employment [DOLE), the IT and Business Process Association of the Philippines (IBPAP), the Technical Education and Skills Development Authority (TESDA), and the competencies of technical and vocational education and training (TVET); 2) Develop a series of industry-led technical vocational education and training programs for Industry 4.0; and 3) Implement an incentive scheme for firms to train employees for 4IR i.e. set up pilot programs and measures in a number of priority industries for Industry 4.0.

\subsection{Singapore}

1) Country scenario composed of its general information relevant to digital economy and its effects from technology disruption and COVID-19 pandemic found been ranking at the top as the world most digital competitiveness for 2019, 2020, Singapore retains as the most competitive country in Asia, including a top spot for Cisco Digital Readiness Index 2019 and the World Economic Forum's Networked Readiness Index 2016. Despite a small population and few natural resources, businesses and residents could get access to not only one of the most technologically advanced digital infrastructure in the world but also a launch equipped with necessary weapons and resources to stand among other nations globally. 
Pandemic was in January 2020 with its performance to be the lowest case of fatality in the world at $0.06 \%$, which is significantly lower than the WHO's global case fatality rate of $4.34 \%$ then considered to be one of the largest and best-organized epidemic control programs in the world. Anyhow the ongoing pandemic is likely to have a significant impact on the local economy. While the policy e-Interview stated that industries that government plans to promote after pandemic are ICT, Electrical Manufacturing, Finance \& Insurance since these are the cores that contribute to GDP.

As Singapore aims for being a Smart Nation, ICT sector is expected to be another key contributor with the ICT 150,000 workers and one-third foreigners within the area of cyber security, data analytics, and software development. However, there is quite a shortage of workers for cybersecurity, software engineers and programmers which recently was solved by importing foreign skilled workers. Though this may make it harder for new graduates in this field which may have to compete in the recruitment with foreigners. While the e-Interview from 13 samples found all agree that digital training should start as early as the secondary school level. Data analysis was mentioned by the majority (13 of 13) as the top field of "must know". Digital Marketing also demanded while programming, coding is still a significant skills. Skills-Future project was frequently mentioned as the popular avenue to promote lifelong learning and updating of skills as shown in Table 4.

2) Digital literacy and Digital skills poised Singapore become Asia's Silicon Valley consist of many IT related firms which required digital skilled related workers. Other sectors are Finance and Insurance also required more IT embedded workers such as FinTech, Mobile Banking, etc. Main skill challenges exist not from the education institutions but the rapid change industries constantly. Survey acknowledge that the digital skills play the major role to determine

Table 4. Top emerging jobs analyzed by WEF, Linkedin, and the current interview 2021.

For Singapore, Data Analyst, Data Scientist, AI and Machine Learning Specialist are top emerging tech-enabled roles beneficiary need for job opportunity/better living.

Across industries ranking Source: World Economic Across industries ranking Source: e-Interview Forum (WEF) Source: LinkedIn

1. Data Analysts and Scientists

1. AI Specialist

2. AI and Machine Learning Specialists

3. Big Data Specialists

4. Digital Marketing and Strategy Specialists

5. Process Automation Specialist 5. Data Scientist
1. Data Analyst, data scientist, data analytics

2. Digital marketer, digital servicer

3. Microsoft Office

4. Cyber Security

5. Programming or Coding 
who will get employed. Data Analyst \& Scientist makes the top similar to Thailand, Indonesia and Malaysia with AI and Data Specialist are necessary profiles to attract the employers.

3) Policy to support digital literacy and digital skills post COVID-19 found numerous programs for mid-career citizens to gain new skills to move into new jobs. Highlighted programs include the Professional Conversion Program (PCP) by Skills Future Singapore and PCP for PMETs (Professionals, Managers, Executives, and Technicians). At the same time, the government tries to cover every digital exclusion, low-income students and low-income adults in the low-income family with the digital inclusion program i.e. 63,000 low income students were provided with NEU-PC Plus Program, Engineer Good Program plus an internet access via Home Access Program (HAP). However, TOUCH Community Services also provided to encourage low-income families to have close assistance in how to use applications in order to have enough confidence and efficacy to new digital literacies. E-Interviews indicate that the elderly and youth could also learn new skills and make use of simple technology to create interest to pursue digital skills further for a lifelong learning.

\subsection{Thailand}

1) Country scenario composed of its general information relevant to digital economy and its effects from technology disruption and COVID-19 pandemic found Thailand 4.0 mission as the economic model driven by innovation, creativity, high-quality, and new technology, employed for boosting the quality of life. This initiative is a stepping stone in the advancement of the country's development focus on rotating the country's labor force into knowledge workers across key economic segments aligned with the 20-year National Digital Economy Masterplan. Industry focus for growth and employment Smart Electronics, Automation and Robotics, Medical \& Wellness Tourism, Digital, and Food for the Future. Digital industries are expected to prosper over the coming years. By 2022, 61\% of Thailand's GDP is predicted to be digitalized, due to growth in every industry driven by digital enhancement.

Pandemic in March 2020 is expected to recover but remains highly uncertain. Its economy is projected to rebound to 4.0 percent in 2021 and further to 4.7 percent in 2022, underpinned by a recovery in domestic demand and supportive fiscal policy. The lockdowns have resulted in a sudden unemployment rate of up to 16.8 percent of the workforce ( 5.69 million people are at risk of losing their jobs). Approximately 520,000 new graduates in the 2020 are at risk of no jobs. $54.1 \%$ of workers choose to study online courses to increase skills and competitiveness by either learning how to prepare for a job such as foreign language skills, digital skills, finance and investment.

Most affected are the informal sector to the loss of income resulted to increase from 4.7 to 11 percent of employment in 2020 under the 3 - 4 waves of pandemic. The National Economic and Social Development Council (NESDC) sounded 
the alarm on soaring unemployment rates in 2021 . One sign is a $9.1 \%$ contraction of GDP for micro and small and medium-sized enterprises (MSMEs); Low and Middle skilled Workers and Youth \& University Graduate are most high risked. Pandemic resulted in a pattern of businesses shifting from the formal sector to the informal affected low skilled, and women workers the most.

2) Digital literacy and Digital skills found the rise of digital infrastructure projects in the country to serve the emerging Jobs analyzed from Linkedin 2020, WEF state the top emerging jobs in Data Analysts \& Scientists, Digital Marketing Specialist, Software and application developer which also aligned with e-Interview found Data Analysts \& Scientists, AI and Machine Learning Specialists, Big Data Specialists, Digital Marketing and Strategy Specialists are topmost. Critical success factors to be successful in the jobs are related to standard hard-skill sets with digital skills embedded. While the e-interview of 36 samples found the most excluded groups are 1) the mid skilled migrant workers and 2) the informal workers with average age range 35 - 45 years old with Degree and High school accordingly. Their current skills are the operating skills i.e. System administrator. Windows Office, Internet, Photoshop, Word press, Basic Coding, Internet Computer Network, Website while their demanding for re-skills are Coding, IoT, e-commerce, digital marketing; and 3) the University Graduates average 20 - 25 years old has moderate digital skills, their demanding digital skills are Digital Designer, Website Designer, Mobile Application Developer, Drone Specialist, SEO designer, Digital Marketer, Digital Copywriter, Programmer, Content Manager as shown in Table 5.

3) Policy to support digital literacy and digital skills post COVID-19 found under 20-year National Digital Economy Masterplan, the government has released massive policies including Digital Economy and Society Development Plan (2017-2036) dedicating to developing human capital towards the digital skills by equipping all workers with appropriate knowledge and skills in preparation for the digital demanding jobs i.e. Ministry of Labor has established DISDA to develop and enhance the digital skills to meet new job demands.

Table 5. Top emerging jobs analyzed by WEF, Linkedin, and the current interview 2021.

Data Analysts, Data Scientists, Digital Marketing Specialist, Software and application developer are top emerging jobs across industries in Thailand.

Across industries ranking Source: World Economic Forum (WEF)

Across industries ranking

1. Data Analysts and Scientists

1. Data Scientist

2. AI and Machine Learning Specialists 2. Back-end Developer

3. Big Data Specialists

3. Data Engineer

4. Full Stack Engineer Specialists

5. Process Automation Specialist
Source: E-Interview

1. Digital Marketer

2. Online marketing

3. Computer Engineer

4. Graphic Designer

5. Stock Photographer 
More policy move for digital skilling are the private sector collaboration, including more targeted incentives, which could help expand such training to a wider group of workers to help reduce skills gaps across industries. Deepen School-Industry Links to Improve Employability of Graduates by driving a formal tripartite mechanism for regular consultation among the government, the industry, and the education institutions for employment, internship, apprenticeship, on-site training.

\subsection{Vietnam}

1) Country scenario composed of its general information relevant to digital economy and its effects from technology disruption and COVID-19 pandemic found placed 67th out of the 141 countries in the Global Competitiveness Report 2019, Structural transformation from agriculture to a modern economy based on foreign direct investment-led manufacturing and the emphasis on "leaving no one behind" boosted living standards. The expansion was driven mainly by industry and construction (10.28\%), service sector (4.30\%), and agriculture, forestry and fisheries (4.11\%). For 2021, the government is targeting economic growth at $6.5 \%$.

Pandemic buffered with solid economic fundamentals and policy buffers, although some structural challenges remain to be addressed. As many as 18,600 companies temporarily suspended business in Q1, up 26 percent year-on-year impacted vastly to tourism, hotel, food industry, export and textile (Both sectors have reported a large number of orders from the E.U., U.S. and China canceled due to coronavirus impacts there). The pandemic hit the economy hard, but Vietnam has taken decisive steps to limit both the health and economic fallout. However, Vietnam's growth in 2020 was the highest in Asia. While the policy e-Interview industry to be promoted after pandemic include non-traditional sectors like finance, insurance, banking, medical technology while high technology focuses on building digital talents to support digitally driven economy.

Labor market was hit hard by pandemic in the second quarter of 2020, particularly the informal sector whom are the low skilled migrant workers, women, youth, and university graduates. Overall, within the industry, $74 \%$ more women than men could be displaced by $4 \mathrm{IR}$ since women are on average found in lower-quality employment than men. In addition, millions of young people in the urban area are unemployed; Less than $15 \%$ of young workers receive technical training, very few have high skills. While the e-interview of 40 samples found the government gives priority to invest in formal workers and university graduates, as they are the core elements of economy. University graduates are the ones with proper foundations to be upgraded with much less efforts than other groups. In addition. Government release many friendly policies to foster the digital transformation at various level. For instance, there are four levels of digital transformation in public services. Each city's local government has their own target of shifting people's habit in using public services from paperwork to fully digitalization. 
Table 6. Top emerging jobs analyzed by WEF, Linkedin, and the current interview 2021.

Data Analyst, Data Scientist, AI and Machine Learning Specialist, and developer are top emerging tech-enabled roles beneficiary need for job opportunity/better living.

\begin{tabular}{|c|c|c|}
\hline $\begin{array}{l}\text { Across industries from } \\
\text { World Economic Forum (WEF) } \\
\text { Ranking }\end{array}$ & $\begin{array}{l}\text { Vietnam IT Landscape 2020| } \\
\text { Vietnam IT Market Report } \\
\text { Q2/2020 By TopDev }\end{array}$ & e-Interview \\
\hline 1. Data Analysts and Scientists & & $\begin{array}{l}\text { 1. Design/Illustration/ } \\
\text { Photoshop }\end{array}$ \\
\hline $\begin{array}{l}\text { 2. AI and Machine Learning } \\
\text { Specialists }\end{array}$ & Data Analyst, DevOps, AI and & 2. Coding/programming \\
\hline 3. Big Data Specialists & $\begin{array}{l}\text { Machine Learning, Web } \\
\text { developers, mobile developers } \\
\text { are highest-paying }\end{array}$ & $\begin{array}{l}\text { 3. Advertising on } \\
\text { FB/Digital marketing }\end{array}$ \\
\hline $\begin{array}{l}\text { 4. Digital Marketing and Strategy } \\
\text { Specialists }\end{array}$ & & 4. Web developing/SQL \\
\hline 5. Process Automation Specialist & & 5. Advanced MS office \\
\hline
\end{tabular}

Technology skill such as using Microsoft Office, basic programing, and advance coding are critical component of the national curriculum 2018 then applied since 2020.

2) Digital literacy and Digital skills found the Agro-processing and logistic services sector hold importance for national employment, growth, international competitiveness, and $4 \mathrm{IR}$ technologies. $41 \%$ of employers in logistics and $31 \%$ of those in Agro-processing, expect productivity improvements of over 25\% from the application of $4 \mathrm{IR}$ by 2030 . The top emerging jobs were analyzed from The Future of Jobs Report (2020), and the e-Interview found Data Analysts \& Scientists, $\mathrm{AI}$ and Machine Learning \& Developer. $84 \%$ of Workers desire to be digital savvy for future employability as shown in Table 6 (ADB 2020 study).

3) Policy to support digital literacy and digital skills post COVID-19 found National Policy, industry, and civil society reveals a range of strategies that seek to improve the readiness of the national workforce for 4IR. Focus on ensuring the agility of education and training to emerging digital skill needs, as well as closer collaboration governments, industry, and civil society nationwide such as an incentive scheme for firms to train employees for Industry 4.0. More policies are: 1) Accelerate workforce digital competency by partnering with private and industry through capacity building of TVET training system; and 2) qualified workforces by industry demands on 4IR skills.

\section{Conclusion}

The Digital Literacy \& Digital Skills Scenario of ASEAN Marginal Workers Under \& Post COVID-19 Pandemic has found as follows:

1) The scenario of workforces relevant with digital literacy and digital skills among all the marginal workers from selected ASEAN countries found affected by the pandemic as well as technology disruption resulted in a pattern of busi- 
nesses shifting from the formal sector to the informal affected low skilled. The future of work has already arrived for a large majority of the online white-collar workforce. Eighty-four percent of employers are set to rapidly digitalize working processes, including a significant expansion of remote work with its trend to change $44 \%$ of their workforce to operate remotely.

2) The scenario of the digital literacy and digital skills relevant to the current and the future jobs skills among all the marginal workers found the top emerging jobs are data analysts \& data scientists, digital marketing specialists, software and application developers, YouTubers and Start Ups. All kinds of administrative jobs, secretaries, accounting, bookkeeping, payroll clerk, HR would be declining.

Most of the marginal workers have low - mid digital skills such as Microsoft office, digital marketing, photoshop, social media, content creating, video editing. Workers are looking forward to reskills in all related digital skills from fundamental to mid and high skills such as data analytic, data science, software development, web development, cybersecurity, AI and programing which are necessary profiles that one must have in-depth knowledge in order to attract all the demanding jobs.

3) The government's policy relevant to support any digital reskill-upskilling among the workforces including the marginal workers to serve well with all demanding skills of the future jobs is found similar in a) Accelerating workforce digital competency by partnering with private and industry sectors through TVET training system; b) Working with industry leader to revamp national curriculums via digital learning pathway and emerging skillsets. The PPP strategy must be used for knowledge transfer and support to build digital ecosystem.

\section{Conflicts of Interest}

The author declares no conflicts of interest regarding the publication of this paper.

\section{References}

Kementerian Pelajaran Malaysia (2012). Laporan Awal Pelan Pembangunan Pendidikan Malaysia 2013-2025.

https://www.scirp.org/(S(i43dyn45teexjx455qlt3d2q))/reference/referencespapers.aspx? referenceid $=1515142$

School of Economics (2016). Research Collection School of Economics. https://ink.library.smu.edu.sg/soe research/1891

Smith, B. (2020). The Digital Skill s Needed in a COVID-19 Economy. https://blogs.microsoft.com/blog/2020/06/30/

Tan, K. S., \& Tang, J. T. H. (2016). New Skills at Work: Managing Skills Challenges in ASEAN. https://ink.library.smu.edu.sg/soe research/1891

The Future of Jobs Report (2020). World Economic Forum Platform for Shaping the Future of the New Economy and Society. 